\title{
Litterfall production in a tropical mangrove of Sarawak, Malaysia
}

\begin{abstract}
Assessment of litterfall production is essential to ascertain the status of nutrient cycling and forest health. Sarawak, Malaysia, is endowed with numerous pristine and estuarine mangroves; however, research on primary productivity of these forests is scanty. Therefore, litterfall production in a pristine Sibuti mangrove of Sarawak was estimated using litter traps for one year (January-December 2013), and forest structure was studied through tree census. The forest was dominated by Rhizophora apiculata (relative density [RD] was 77.11\%), followed by Xylocarpus granatum (RD was 16.92\%) and other species (RD was only 5.97\%). The annual dry weight of litterfalls was estimated to be $1640.82 \mathrm{~g} \mathrm{~m}-2$, of which R. apiculata contributed $92.94 \%$, followed by X. granatum (4.01\%) and other species (3.05\%). Leaves were the most abundant $(57.21 \%)$ contributory component of litters, followed by propagules $(11.89 \%)$, flowers $(10.85 \%)$, twigs $(8.56 \%)$, and stipules $(8.45 \%)$. No significant correlations were found for total litterfall and its major components with climatic variables and forest structure. Total litterfall of R. apiculata and X. granatum did not show any seasonal variations. However, leaf litter of R. apiculata showed a significant seasonal variation between intermediate (JanuaryApril) and wet (September-December) seasons. The litterfall production of Sibuti mangrove forest is higher in comparison to other tropical mangroves of the world. The higher productivity of the forest could be due to nutrient availability, pristine nature, and stand maturity of the forest rather than climatic influences. The findings of the study suggest that litterfall production of the pristine Sibuti mangrove is not influenced by the variability of climatic factors.
\end{abstract}

Keyword: Litter production; Rhizophora apiculata; Seasonal variation; Sibuti mangrove; Sarawak 